\title{
SEROPREVALENCE OF MYCOPLSMA MYCOIDES CLUSTER IN SMALL RUMINANT USING MONOCLONAL ANTIBODY- BASED C ELISA IN DAKAHILIA PROVINCE
}

\author{
EMAD YOUNIS $^{*}$; YASSER ELNAKER ${ }^{* *}$; NERMIN AWAD ${ }^{* * *}$ and DINA ELSHAFEY ${ }^{* * * *}$ \\ * Department of Internal Medicine and Infectious Diseases, Fac. Vet. Med., Mansoura University. \\ ** Department of Animal Medicine, Fac. Vet. Med. New Vally, Assiut University. \\ **** Department of Microbiology, Fac. Vet. Med. Mansoura University. \\ ***** Department of Mycoplasma. Animal Health Research Institute, Dokii, Cairo.
}

Email: yasserelnaker@yahoo.com \& yasserelnaker@vetnv.au.edu.eg, _ Assiut University web-site: www.aun.edu.eg

\section{ABSTRACT}

Received at: 3/6/2015

Accepted: 24/6/2015
In this study, 1103 sheep and goat at five different localities in Dakahilia Governorate, Egypt, during a period from November 2013 until March 2014 were examined clinically for respiratory manifestation. a total of 212 sheep and goat with different ages showing respiratory manifestations. Serum samples from diseased animals were examined using monoclonal antibody-based C ELISA Kit for Diagnosis of CBPP to study the prevalence of Mycolpasma mycoides cluster. Our result revealed that, prevalence of Mycoplasma spp was (52.35\%) in both sheep and goat while there are higher significance between species $\mathrm{P}<0.05$ and odds ratio $=0.3381$ it was higher in goat $(67.81 \%)$ than in sheep $(41.6 \%)$ moreover, they are higher significance between two age groups $\mathrm{P}<0.05$ and odds ratio equal 2.2722 it was higher in young animals $<2$ year than in adult $>2$ year old age $(60.29 \%)$ and $(38.15 \%)$ respectively.

Keywords: Mycoplasma, C ELISA, small ruminant.

\section{INTRODUCTION}

Members of the genus Mycoplasma belong to the most important bacterial livestock pathogens worldwide. Of particular importance are Mycoplasma mycoides subsp. mycoides (Mmm) and Mycoplasma capricolum subsp. capripneumoniae (Mccp), two members of the 'Mycoplasma mycoides cluster' (Cottew et al., 1987), which are responsible for contagious bovine pleuropneumonia (CBPP) and contagious caprine pleuropneumonia (CCPP), respectively. Both diseases cause significant losses in livestock, in particular in Africa and Asia, and are a threat to disease-free countries. The Mycoplasma mycoides cluster is made up of six species, subspecies or group of strains that are pathogenic for ruminants. It includes two biotypes of $\mathrm{M}$. mycoides subsp. mycoides, the small-colony (MmmSC) and large-colony (MmmLC) biotypes, M. mycoides subsp. capri (Mmc), M. capricolum subsp. capricolum (Mcc), M. capricolum subsp. capripneumoniae, formerly M. sp type F38 (Mccp) (Bonnet et al., 1993; Leach et al., 1993) and the bovine group 7 of Leach (BG7). They all share numerous genotypic or phenotypic traits. The 16S rRNA genes of $M m c$ and $M m m L C$ are $99.9 \%$ similar, suggesting they should be considered as two phenotypes of the same species, distinct from MmmSC (Monnerat et al.,1999 and Pettersson et al., 1996); (iv) Animal host specificity, previously thought as very specific and used as a clue to identification, has proven to be unreliable (Nicolet,1996). Contagious caprine pleuropneumonia (CCPP) is a highly contagious, infectious fibrinous pleuropneumonia of goats caused by Mycoplasma capricolum subsp.capripneumoniae (Mccp), characterized by fever, respiratory distress with coughing, nasal discharge, high morbidity and mortality rates (Radostitis et al., 2006). Its economic importance is due to direct loss which result from its high mortality, reduced milk yield, cost of treatment and vaccination of the disease and indirect loss due to the imposition of trade restrictions. It has been reported from more than 35 countries most of which are in Africa. However, the exact distribution of the disease is not yet known mainly due to the lack of sensitivity and specificity of the diagnostic tests and difficulty of identification of the organism causing the disease (Nicholas, 2002).

Competition enzyme-linked immunosorbent assay (c-ELISA) is a newly developed test, which permits the specific detection of antibodies in animals, which have been affected by CCPP (Thiaucourt et al., 1994). This test is based on the use of a monoclonal antibody (MAb), which is competing with goat antibodies to bind to the antigen that is coated on the plates. The specificity of the test depends on the epitope that recognized by the MAb. The introduction of the c-ELISA for CCPP will permit the implementation of serological enquiries on a large scale for the first time. This test combines the well-known advantages of the 
ELISA format with the specificity provided by the use of a MAb. Thiaucourt et al. (1996)

However, information on seroprevalence and associated risk factors were scanty. Therefore, the objectives of this study were to determine the seroprevalence of CCPP in small ruminant in five localities in Dakahilia Governorates, Egypt, and to identify the risk factors responsible for the occurrence of the disease.

\section{MATERIALS and METHODS}

\section{Animals (sheep and goat):}

During a period from November 2013 until March 2014 a total of 1103 sheep and goat (764 sheep and 339 goats), located in five different localities in Dakahilia province, were examined clinically for respiratory manifestation, each animal show one or more from the following signs (dyspnea, cough, nasal discharge ranged from serous to purulent, rapid breathing) were blood sampled and their data were recorded for seroprevalence of mycoplama spp. in sheep and goat in Dakahlia province. The sheep and goat under study were raised mixed in the same area in morning and at night were kept in closed pen, the sheep and goat were illustrated in table (1).

Table 1: Sheep and goat examined according to localities.

\begin{tabular}{cccc}
\hline Flock No & $\begin{array}{c}\text { Total } \\
\text { (Sheep + Goat) }\end{array}$ & Sheep & Goat \\
\hline El-Mansoura & 165 & 140 & 25 \\
\hline Talkha & 224 & 154 & 70 \\
\hline Sherbin & 192 & 110 & 82 \\
\hline Belkas & 282 & 180 & 102 \\
\hline Dikrins & 240 & 180 & 60 \\
\hline Total & $\mathbf{1 1 0 3}$ & $\mathbf{7 6 4}$ & $\mathbf{3 3 9}$ \\
\hline
\end{tabular}

\section{1-Samples}

Two hundred and twelve blood samples collected from each sheep and goat showing respiratory manifestation through the jugular vein of each animal using plain vacutainer tubes. The blood allowed clotting for 1-2 hrs. at room temperature, stored horizontally overnight at $4^{\circ}$ C. Serum separated from the clot by centrifugation at 2000-3000 rpm for 10-15 minutes, the serum labeled and stored at $-20^{\circ} \mathrm{C}$, then transported on ice in icebox to Mycoplasma Department, Animal Health Research Institute.

\section{2- Serological detection of mycoplasma antibodies} (OIE 2014) and SANCO/AH/R25/2001:

ELISA kits \{monoclonal antibody-based C ELISA, named Mab 117/5 (CIRAD / Institute POURQUIER CBPP serum competition ELISA - Version P05410/02 - Page 1/5). were used for detection of mycoplasma mycoides subspecies mycoides (large Colony $\mathrm{Mmm}$ LC) antibodies. This kit has been evaluated by the Joint Division FAO/AIEA within the framework of a Coordinated Research Project (CRP).

\section{The principle of the test is:}

1) Serum samples to be tested are diluted and mixed with the specific monoclonal antibody (Mab 117/5) in a dilution plate or "pre-plate". This mixture transferred into the MmmSC coated micro plate. Any specific antibodies present in the test sera will bind to the Mmm SC antigen, competing with the Mab for the specific epitope.
2) After washing, an anti-mouse IgG serum conjugated to horseradish peroxidase (HRP), which will bind to any Mab fixed to the wells, is added. If specific $M m m S C$ antibodies are present in the bovine sera, they will displace the Mab and the conjugate will not be able to bind.

4) Following another series of washes, the HRP substrate (TMB) is added, forming a blue compound that will turn to yellow when the reaction is stopped. The intensity of the color is an inverse measure of the proportion of $M m m S C$ antibodies present in the test sera. The cut-off point is calculated using the results obtained from a monoclonal control $(\mathrm{Cm}$, $0 \%$ inhibition) and a conjugate control ( $\mathrm{Cc}, 100 \%$ inhibition). Positive and negative control sera delivered within the kit.

\section{Reading and Interpretation.}

a) Read the OD at $450 \mathrm{~nm}$ (OD450). The photometer could first be blanked on air.

b) Calculate the mean value of the $\mathrm{Cm}$ ( $0 \%$ inhibition) and $\mathrm{Cc}$ (100\% inhibition) controls.

c) Calculate the percentage of inhibition (PI) for each serum as follows:

$\mathrm{PI}=100 \times[(\mathrm{OD} \mathrm{Cm}-$ OD Test $) /(\mathrm{OD} \mathrm{Cm}-\mathrm{OD} \mathrm{Cc})]$

- Sera with a PI equal to or lower than $40 \%$ considered negative.

- Sera with PI between 40 and 50\% considered 
doubtful.

- Sera with PI equal to or greater than $50 \%$ considered positive.

\section{Statistical Analysis}

The odds ratio and $\mathrm{P}$ value were calculated according to the method described by Altman (1991).

\section{RESULTS}

\section{Clinical examination:}

Clinical examination of 1103 sheep and goat revealed that, total of $212(19.2 \%)$, sheep and goat show respiratory manifestation as dyspnea, cough, nasal discharge, for sheep 125 out of 764 ( 16.36\%) sheep examined show respiratory manifestation while in goat the respiratory manifestation reach $25.66 \%$ (87 from 339 examined).the respiratory manifestation. Testing of blood samples from diseased animals (212) using ELISA technique, revealed that, Table (2) \& Fig (1) mycoplasma mycoides seroprevalence in sheep and goat has respiratory manifestation reach $52.35 \%$ (111 out of 212 examined), while in goat only reach $67.81 \%$ (59 out of 87 examined), in sheep only reach $41.6 \%$ (52 out of 125 examined).

Table 2: Seroprevalence of Mycoplasma mycoides cluster in sheep and goat using ELISA kit.

\begin{tabular}{cccccccccc}
\hline \multirow{2}{*}{$\begin{array}{c}\text { Lpecies } \\
\text { Locality }\end{array}$} & \multicolumn{2}{c}{ Total sheep and goat } & \multicolumn{3}{c}{ Goat } & \multicolumn{3}{c}{ Sheep } \\
\cline { 2 - 10 } El-Mansoura & Total & Positive & $\mathbf{\%}$ & Total & Positive & $\mathbf{\%}$ & Total & Positive & $\%$ \\
\hline Talkha & 70 & 41 & 58.57 & 40 & 30 & 75 & 30 & 11 & $\mathbf{3 6 . 6 6}$ \\
\hline Sherbin & 32 & 12 & 37.5 & 16 & 8 & 50 & 16 & 4 & $\mathbf{2 5}$ \\
\hline Belkas & 30 & 15 & 50 & 11 & 7 & 63.63 & 19 & 8 & $\mathbf{4 2 . 1}$ \\
\hline Dikrins & 40 & 18 & 45 & 20 & 14 & 70 & 20 & 4 & $\mathbf{2 0}$ \\
\hline Total & $\mathbf{2 1 2}$ & $\mathbf{1 1 1}$ & $\mathbf{5 2 . 3 5}$ & $\mathbf{8 7}$ & $\mathbf{5 9}$ & $\mathbf{6 7 . 8 1}$ & $\mathbf{1 2 5}$ & $\mathbf{5 2}$ & $\mathbf{4 1 . 6}$ \\
\hline Between species & \multicolumn{2}{c}{ Odds ratio $=0.3381$} & & $95 \% \mathrm{CI}=0.1905$ to 0.5998 & & $\mathrm{P}=0.0002$ &
\end{tabular}

Fig. 1: Seroprevalence of Mycoplasma Mycoides in sheep and goat using ELISA kit

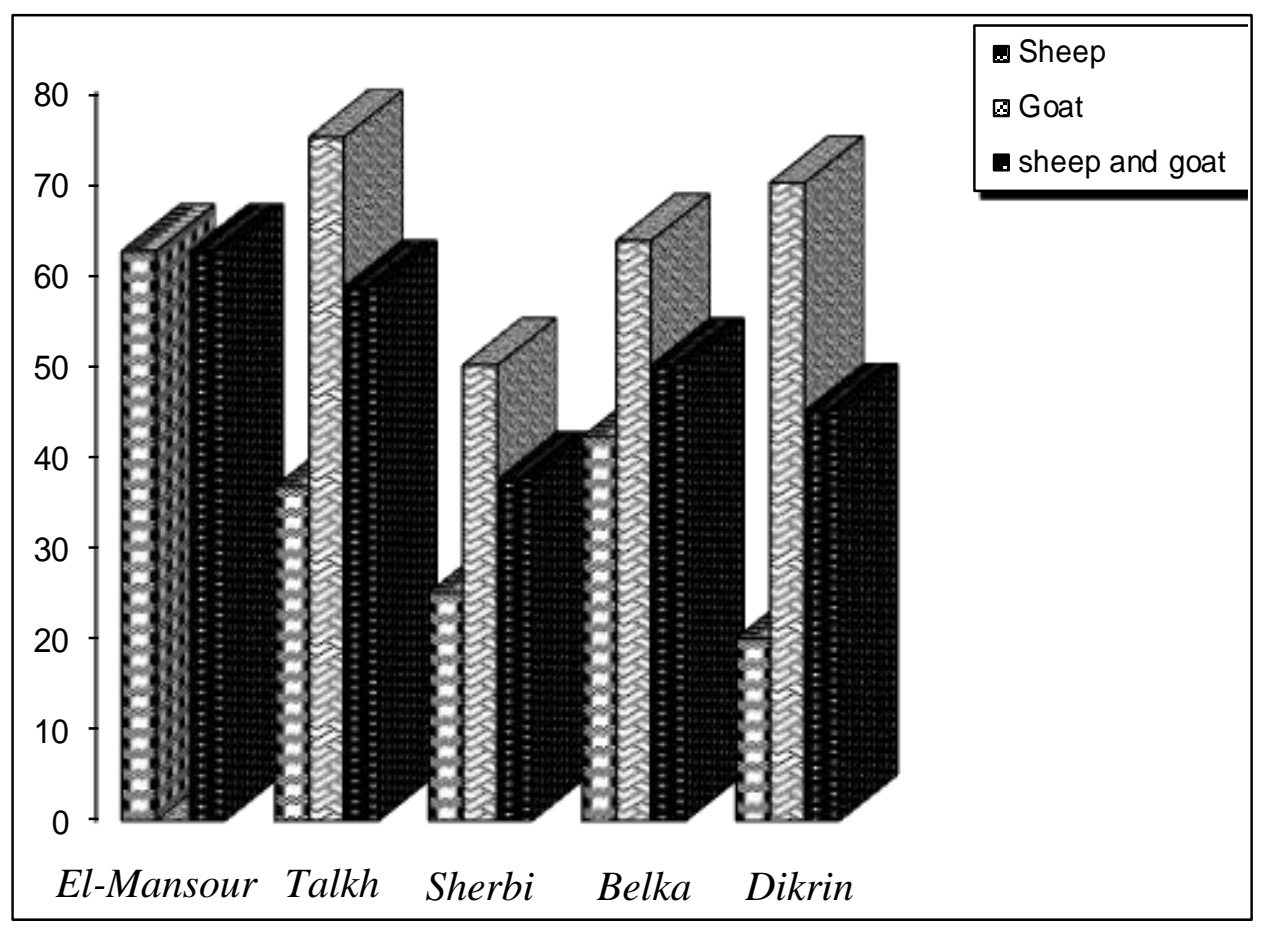

Age seroprevalece of mycoplasma mycoides revealed that, the higher seroprevalence were recorded in age less than 2 year old, $(60.29 \%),(77.96 \%)$ and $(46.75 \%)$ in (sheep and goat), goat only and sheep only respectively , while adult sheep recorded low seroprevalence as it reach $38.15 \%, 46.42 \%$ and $33.33 \%$ in (sheep and goat), goat only and sheep only respectively. (Table 3 ). 
Assiut Vet. Med. J. Vol. 61 No. 146 July 2015

Table 3: Age seroprevalence of Mycoplasma mycoides in sheep and goat using ELISA kit.

\begin{tabular}{cccccccccc}
\hline Age & \multicolumn{2}{c}{ Total sheep and goat } & \multicolumn{3}{c}{ Goat } & \multicolumn{3}{c}{ Sheep } \\
\hline & Total & positive & $\%$ & Total & Positive & $\%$ & Total & Positive & $\%$ \\
\hline Less than 2 year & 136 & 82 & 60.29 & 59 & 46 & 77.96 & 77 & 36 & 46.75 \\
\hline Over than 2 year & 76 & 29 & 38.15 & 28 & 13 & 46.42 & 48 & 16 & 33.33 \\
\hline Total & $\mathbf{2 1 2}$ & $\mathbf{1 1 1}$ & $\mathbf{5 2 . 3 5}$ & $\mathbf{8 7}$ & $\mathbf{5 9}$ & $\mathbf{6 7 . 8 1}$ & $\mathbf{1 2 5}$ & $\mathbf{5 2}$ & $\mathbf{4 1 . 6}$ \\
\hline Between Age & $\mathrm{P}=0.0053$ & Odds ratio & $\mathbf{2 . 2 7 2 2}$ & $\mathbf{9 5} \%$ CI $\mathbf{1} \mathbf{1 2 7 5 6}$ to $\mathbf{4 . 0 4 7 3}$ & & &
\end{tabular}

Between Age $\quad \mathrm{P}=0.0053$ Odds ratio $=\mathbf{2 . 2 7 2 2} \quad 95 \% \mathrm{CI}=\mathbf{1 . 2 7 5 6}$ to 4.0473

Fig. 2: Age seroprevalence of Mycoplasma mycoides in sheep and goat using ELISA kit.

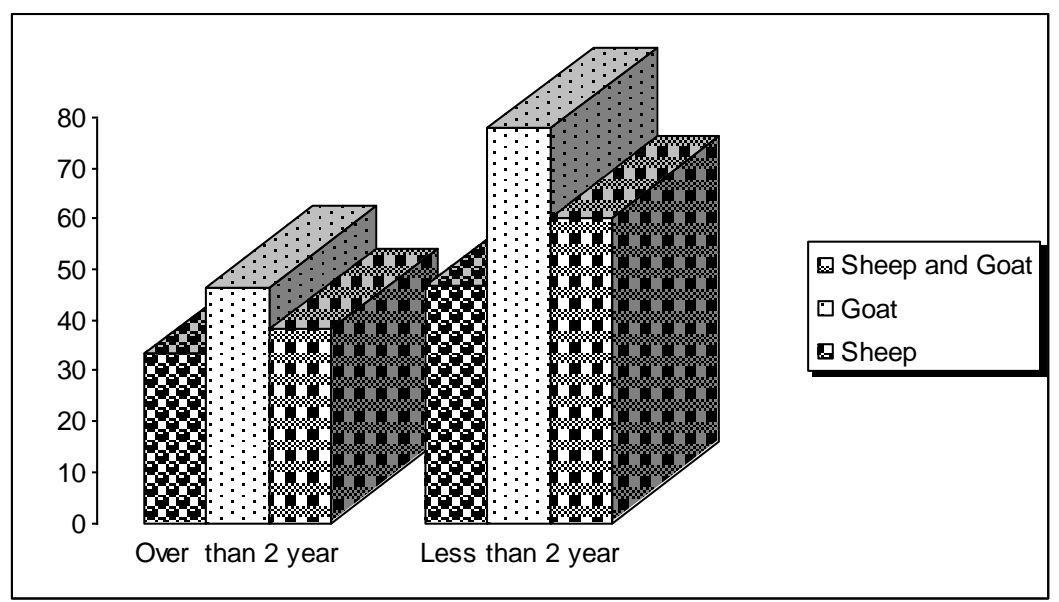

\section{DISCUSSION}

On examing seroprevalence of Mycoplasma spp in sheep and goat in Dakahilia governorate and studying their role in respiratory manifestation and risk factors associated with its seroprevalence a total of 1103 sheep and goat were examined clinically for respiratory signs, the result revealed that, total of 212 (19.2\%), sheep and goat show respiratory manifestation as dyspnea, cough, nasal discharge, for sheep 125 out of 764 (16.36\%) sheep examined show respiratory manifestation while in goat the respiratory manifestation reach $25.66 \%$ (87 from 339 examined).

The OIE reference method for CBPP serology is the complement fixation test (CFT). This technique has been used for CBPP eradication campaigns in many countries. However, it presents some disadvantages, particularly due to the existence of non-specific positive results and to difficulties encountered in the standardization of antigen production. For these reasons CIRAD-UMR15 (FAO and OIE world reference center for (CBPP) has developed another test, a competition ELISA (C-ELISA) based on a monoclonal anti-Mmm SC antibody, named Mab $117 / 5$. This test is an alternative to the CFT for the OIE and can be used for official CBPP testing. Regalla et al. (2000). According to phenotypic and genotypic characteristics that cause cross-reactions in conventional diagnostic techniques between the five Mycoplasmas, spp. that called "Mycoides cluster" (Manso-Silvan et al., 2007) Its closest relatives are Mycoplasma capricolum subsp. capricolum and Mycoplasma leachii, which may cross-react with Mccp, but the other members of the mycoides cluster, such as Mycoplasma mycoides subsp capri or Mycoplasma mycoides subsp. mycoides, may also share similarities. $\mathrm{MmmSC}$ is a mycoplasma, i.e. a wall-less bacteria (mollicute), belonging to the so-called "mycoides cluster" The closest relative to MmmSC is $M$. mycoides susbp capri $(M m c)$, which is usually found in goats. (OIE 2014) and SANCO/AH/R25/2001.

In our study the overall seroprevalence of mycoplasma spp in sheep and goat were 52.35\% (111 out of 212 examined), while there are higher significance between species $\mathrm{P}<0.05$ and odds ratio $=0.3381$. In goat only the seroprevalence reach $67.81 \%$ (59 out of 87 examined), while in sheep only the seroprevalence reach $41.6 \%$ (52 out of 125 examined). Moreover, theirs variations in seroprevalence between localities as showed in Table (2) \& Fig. (1), the obtained result is agreed with the result obtained by Sharew et al. (2005). They made a comparison of serological tests 
for CCPP; sera from 767 goats examined. They were subjected to three tests: complement fixation test (CFT) with Mycoplasma capricolum subspecies capripneumoniae antigen; blocking ELISA (B-ELISA) with Mycoplasma capricolum subspecies capripneumoniae antigen; and CFT with Mycoplasma mycoides subspecies mycoides small colony type antigen. Antibodies were detected by these three tests in $23 \%, 2 \%$ and $12 \%$, respectively, of sera from districts in which CCPP had not been reported, and in $60 \%, 83 \%$ and $87 \%$, respectively, in sera from areas in which CCPP had been reported. Moreover, added that the use of B-ELISA test for the diagnosis and for epidemiological studies of CCPP strongly recommended. And the obtained result are nearly higher than the result obtained by Al-Momani et al. (2011) they examined 18 sheep flocks, 27 goat flocks, and 59 mixed flocks containing both sheep and goats in northern Jordan against ycoplasma mycoides subspecies capri using the latex agglutination test. To increase the chances of detecting positive flocks, sick or older ewes were sampled. Specific information was obtained using a questionnaire to identify potential risk factors for $M$. mycoides subsp. capri seropositivity in small ruminants. The true flock-level seroprevalences of $\mathrm{M}$. mycoides subsp. capri were $34 \%, 32 \%$, and $38 \%$ in small ruminants (sheep and goats), sheep, and goats respectively, the difference in result may be due to difference in test using and locality.

In regarding to age as second risk factors they are higher significance between two age groups $\mathrm{P}<0.05$ and odds ratio equal 2.2722, (Table 3 ) in our study the higher seroprevalence higher seroprevalence were recorded in age less than 2 year old, (60.29\%), $(77.96 \%)$ and $(46.75 \%)$ in (sheep and goat), goat only and sheep only respectively, while adult sheep recorded low seroprevalence as it reach $38.15 \%$, $46.42 \%$ and $33.33 \%$ in (sheep and goat), goat only and sheep only respectively. The obtained result is differ from the result obtained by Eskindir et al. (2012), they studied seroprevalnce of mycoplasma Capri in two age group of sheep, age group $\leq 2$ years(young), age group $>2$ years (adult). The seroprevalence of CCPP was significantly $(\mathrm{P}<0.05)$ higher in adult $(7.38 \%)$ than in young $(1.05 \%)$ goats added that, there was non-significant variation concerning the risk involvement of she-goat (4.67\%) and buck (5.32\%) in the flock. In addition, APHRD (2010) stated that age is an important factor and all ages can be affected. Seropositivity may be high in adult but mortality is higher in young animals than in adults Radostits et al. (2007). The differences may be attributed to flock size increase, the chance of contact between animals increase, which enhance chance of acquiring the infection. Being a contagious infection, the chances of spread of CCPP was maximum in large flock where the husbandry practices were not efficiently available and the individual animal care was not appropriately possible.

The goat has a higher seroprevalence than sheep (Table 2), these results are discussed by Elsawalhy (2012), who mentioned that, Goats are highly susceptible to natural infection and the pathogen has been isolated from sheep with typical lesions, Added that Housing goats together facilitate spread of the disease.

From our result we can concluded that, CCPP can be diagnosed by ELISA kit used to diagnose CBPP and CCPP need further studies in studying areas and isolation and identification of Mycoplasma Mycoides subspp Capri and studying all risk factors associated with disease transmission to initiate preventive control measures.

\section{REFERENCES}

Al-Momani, W.; Abo-Shehada, MN. and Nicholas, RA. (2011): Seroprevalence of and risk factors for Mycoplasma mycoides subspecies capri infection in small ruminants in Northern Jordan. Trop Anim Health Prod. 43(2): 463-9.

Altman, DG. (1991): Practical statistics for medical research. London: Chapman and Hall.

APHRD (2010): Animal and Plant Health Regulatory Directorate, Ministry of Agriculture: Status of Major Animal Diseases in Ethiopia. Version 1, Addis Ababa, Ethiopia.

Bonnet, F.; Saillard, C.; Bove, J.M.; Leach, R.H.; Rose, D.L.; Cottew, G.S. and Tully, J.G. (1993): DNA relatedness between ®eld isolates of Mycoplasma F38 group, the agent of contagious caprine pleuropneumonia, and strains of Mycoplasma capricolum. Int. J. Syst. Bacteriol. 43, 597 \pm 602 .

Cottew, GS.; Breard, A.; DaMassa, AJ.; Erno, H. and Leach, RH. (1987): Taxonomy of the Mycoplasma mycoides cluster. Isr J Med Sci 23: 632-635.

Elsawalhy (2012): Contagious caprine pleuropneumonia in Veterinary Infectious Diseases, A guide for practitioners and students $3^{\text {rd }}$ Edition Pp 292.

Eskindir Yousuf, Achenef Melaku and Basaznew Bogale (2012): Seroprevalence of contagious caprine pleuropneumonia in Dire Dawa provisional administrative council, Eastern Ethiopia. J. Vet. Med. and Animal Health. 4(7), pp. 93-96

Leach, R.H.; Ernù, H. and Macowan, K.J. (1993): Proposal for the designation of F38-type caprine mycoplasmas as Mycoplasma capricolum subsp. capripneumoniae subsp. nov. and consequent obligatory relagation of strains currently classi®ed as M. capricolum (Tully, Barile, Edward, Theodore, and Ernù 1974) to an additional new subspecies $M$. 
capricolum subsp. capricolum subsp.nov. Int. J. Syst. Bacteriol. 43, 603 - 605.

Manso-Silvan L.; Perrier, X. and Thiaucourt, F. (2007): Phylogeny of the Mycoplasma mycoides cluster based on analysis of five conserved protein-coding sequences and possible implications for the taxonomy of the group. Int. J. Syst. Evol. Microbiol., 57, 2247-2258.

Monnerat, M.P.; Thiaucourt, F.; Poveda, J.B.; Nicolet, J. and Frey, J. (1999): Genetic and serological analysis of lipoprotein LppA in Mycopasma mycoides subsp. mycoides LC and Mycoplasma mycoides subsp. capri, Clin. Diagn. Lab. Immunol. 6 224-230.

Nicholas, R.A.J. (2002): Contagious Caprine pleuropneumonia. In: Tempesta M. Ed.), Recent Advances in Goat Disease. International Veterinary Information Service (IVIS), Ithaca Ny (www.ivis.org.); A09070802: available at file: //A:ICCPP.HTM accessed on 20/04/2008 pp. 1-6.

Nicolet, J., Animal mycoplasmoses (1996): a general introduction, Rev. Sci. Tech. Off. Int. Epizoot. 15 1233-1240.

OIE (2014): OIE Terrestrial Manual 2014: Chapter 2.4.9. - Contagious bovine pleuropneumonia.

Pettersson, B.; Leitner, T.; Ronaghi, M.; Bölske, G.; Uhlèn, M. and Johansson, K.E. (1996): Phylogeny of the Mycoplasma mycoides cluster as determined by sequence analysis of the $16 \mathrm{~S}$ rRNA genes from the two rRNA operons, J. Bacteriol. 178 4131-4142.

Radostitis, O.M.; Gay, C.C.; Hinchliff, W.K. and Constable, D.P. (2006): Veterinary Medicine.
A Text Book of the Disease of Cattle, Sheep, Pigs, Goats and Horses. 10 ${ }^{\text {th }}$ Edition, W.B. Saunders Company Ltd. London: pp. 1140-1141.

Radostits, OM.; Blood, DC. and Cray, CC. (2007): Veterinary Medicine: A textbook of the disease of cattle, sheep, goats, pigs and horses. $8^{\text {th }}$ eds, Baillier Tindall. London, pp. 1214.

Regalla, J. and Lefevre, P.C. (2000): Contagious bovine pleuropneumonia (chapter 2.4.6), in "Manual of standards for diagnostic tests and vaccines" OIE, 12 rue de Prony 75017 Paris France; 503-514.

SANCO/AH/R25/ (2001): Report of the scientific Committee on Animal Health and Animal welfare Adopted 17 October 2001 EUROPEAN COMMISSION.

Sharew, A.D.; Staak, C.F. and Thiaucourt, F. Roger (2005): A Serological Investigation into Contagious Caprine Pleuropneumonia (CCPP) in Ethiopia Tropical Animal Health and Production January 2005, Volume 37, Issue 1, pp 11-19.

Thiaucourt, F.; Deswetchin, C.; King, G.E. and Libeau, G. (1994): The use of a blocking ELISA for the specific detection of antibodies to Mycoplasma sp. type F38 (CCPP). IOM Letters, 3, 21-22.

Thiaucourt, F.; Bolske, G.; Leneguersh, F.; Smith B. and Wesonga, H. (1996): Diagnosis and control of contagious caprine pleuropneumonia. Rev. sci. tech. Off. int. Epiz., 1996, 15 (4), 1415-1429.

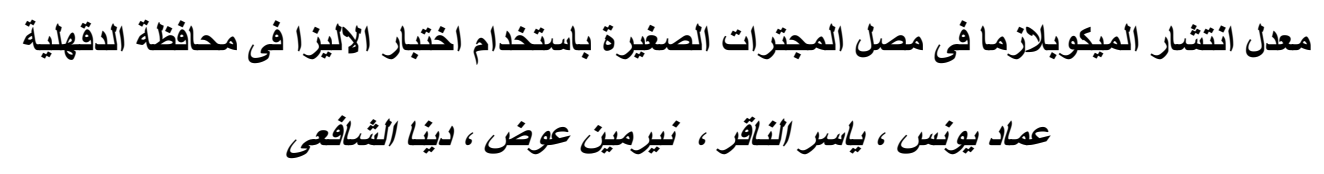

Email: yasserelnaker@yahoo.com \& yasserelnaker@vetnv.au.edu.eg, Assiut University web-site: www.aun.edu.eg

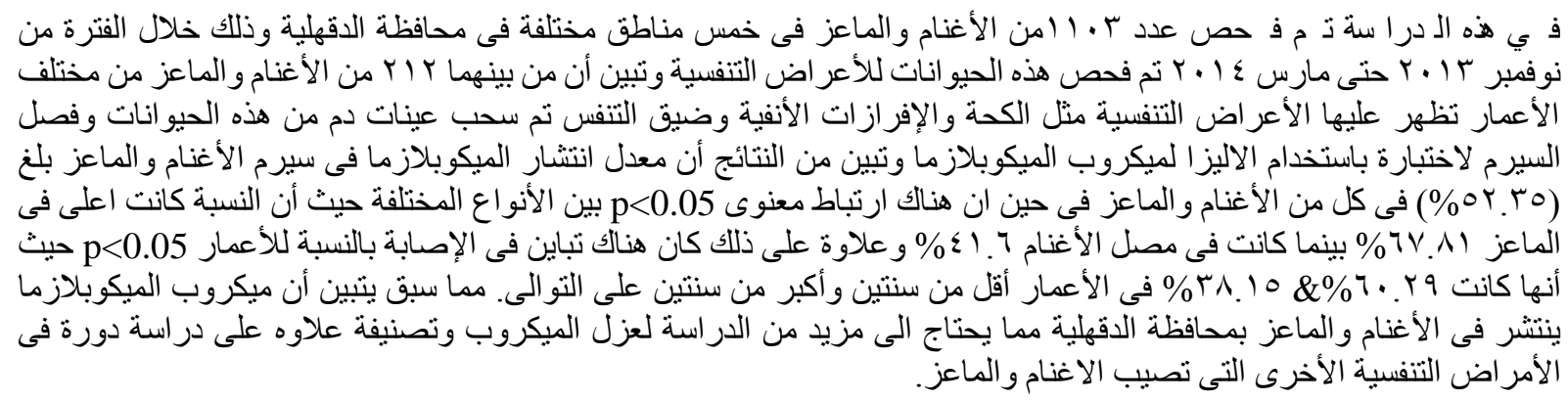

